\title{
Recent Topical Research on Global, Energy, Health \& Medical, and Tourism Economics, and Global Software: An Overview
}

\author{
Chia-Lin Chang ${ }^{1}$ and Michael McAleer-6, \\ ${ }^{1}$ Department of Applied Economics, Department of Finance, National Chung Hsing University, Taiwan \\ ${ }^{2}$ Department of Quantitative Finance, National Tsing Hua University, Taiwan \\ ${ }^{3}$ Discipline of Business Analytics, University of Sydney Business School, Australia \\ ${ }^{4}$ Econometric Institute, Erasmus School of Economics, Erasmus University Rotterdam, Netherlands \\ ${ }^{5}$ Department of Quantitative Economics, Complutense University of Madrid, Spain \\ ${ }^{6}$ Institute of Advanced Sciences, Yokohama National University, Japan
}

\begin{abstract}
The paper presents an overview of recent topical research on global, energy, health \& medical, and tourism economics, and global software. We have interpreted "global" in the title of the Journal of Reviews on Global Economics to cover contributions that have a global impact on economics, thereby making it "global economics". In this sense, the paper is concerned with papers on global, energy, health \& medical, and tourism economics, as well as global software algorithms that have global economic impacts. The topics covered include re-opening the Silk Road to transform Chinese trade, education and skill mismatches, code of practice and indicators for quality management of official statistics, projections of energy use and carbon emissions, multi-fuel allocation for power generation using genetic algorithms, optimal active energy loss with feeder routing and renewable energy for smart grid distribution, demand for narcotics with policy implications, computer technology to improve medical information, heritage tourism, ecotourism impacts on the economy, society and environment, taxi drivers' cross-cultural communication problems and challenges, hybrid knowledge discovery system based on items and tags, game development platform to improve advanced programming skills, quadratic approximation of the newsvendor problem with imperfect quality, classification of workflow management systems for emails, academic search engine for personalized rankings, creative and learning processes using game-based activities, personal software process with automatic requirements traceability to support start-ups, and comparing statistical and data mining techniques for enrichment ontology with instances.
\end{abstract}

Keywords: Global economics, energy economics, health \& medical economics, tourism economics, global software.

\section{INTRODUCTION}

The paper presents an overview of recent topical research on global, energy, health \& medical, and tourism economics, and global software. We have interpreted "global" in the title of the Journal of Reviews on Global Economics to cover contributions that have a global impact on economics, thereby making it "global economics". The focus is on recent topical research on important issues in Thailand, but the ideas and methods involved are portable for any country, regardless of their current stage of economic advancement.

Contributors to the special issue are from Thailand, Taiwan, Australia and USA. Most of the papers were presented at the International Conference on Economics, Finance and Statistics (ICEFS 2017), Hong Kong, China, in January 2017, while the remaining

*Address of correspondence to this author at the Department of Quantitative Finance, National Tsing Hua University, Taiwan; Tel: +886-3-571-5131 ext. 62534; Fax: +886-3-562-1823; E-mail: michael.mcaleer@gmail.com JEL: I15, L86, O13, Q47, Z32. papers were presented at 6th International Workshop on Computer Science and Engineering (WCSE 2016), June 2016, Tokyo, Japan, 5th International Conference on Network, Communication and Computing (ICNCC 2016), December 2016, Kyoto, Japan, 5th International Conference on Learning Innovation in Science and Technology (ICLIST2016), January 2016, Pattaya, Thailand, and 7th International Conference on Information Technology and Electrical Engineering (ICITEE 2015), October 2015, Chiang Mai, Thailand. Each conference paper was reviewed by two independent referees, and the revised versions were subsequently reviewed by the two Guest Co-editors of the special issue. The 19 papers include 3 papers on global economics, 3 papers on energy economics, 2 papers on health $\&$ medical economics, 3 papers on tourism economics, and 8 papers on global software.

\section{OVERVIEW}

This section provides an overview of the 19 papers across five broad topics. The 3 papers on global economics are as follows. The first paper is by Ning Mao (China-ASEAN International College, Dhurakij 
Pundit University, Thailand), and Michael McAleer (National Tsing Hua University, Taiwan) on "Reopening the Silk Road to Transform Chinese Trade". Under anti-globalization and isolationism, China is seeking to portray itself as a new leader for globalization under the banner of the Silk Road initiative. Meanwhile, China's traditional and comparatively advantaged industry, silk, has faced dire predicaments and challenges for long time, and needs a transformation in terms of initiatives. Throughout history, the prosperity arising from silk was supposed to represent a microcosm of Chinese society. This paper searches the breakthrough point to improve the current dilemma of Chinese silk enterprises; uses a Case Study for inductive reasoning that is feasible for marketing strategies; and provides a strategy to help Chinese silk enterprises to transform their market positioning and operating modes to obtain better development opportunities. The paper also analyzes the new external environment based on the "One Belt, One Road" principle, which is of crucial importance for the implementation of new marketing strategies.

"Education and Skill Mismatches in Maptaphut Industrial Estate, Thailand" is the second paper by Duangjan Varakamin (College of Innovative Business and Accounting, Dhurakij Pundit University, Thailand). The paper examines educational and skill mismatches by using primary data from Maptaphut Industrial Estate, Rayong Province, Thailand, conducted from 226 respondents. Ordinary least squares (OLS) and unconditional quantile (UQR) regressions are used to examine the mismatches on earnings. The empirical findings are as follows: (1) returns to education of high income workers are larger than average income workers; (2) education mismatches affect earnings, such that over-education is statistically significant, whereas under-education is not significant, for both the OLS and UQR estimates; (3) UQR provides more information on size of the over-education to the returns on schooling; (4) specific training for some job positions also indicates educational and skill mismatches; and (5) firms should invest in training for workers to reduce weaknesses in educational mismatches.

The third paper on global economics is by Titirut Mekbunditkul (Research Service Centre, Dhurakij Pundit University, Thailand), and Sorachai Phisalbutr (Retired Government Official, Thailand) on "Development of a Code of Practice and Indicators for Quality Management of Official Statistics in Thailand". The paper is concerned with the National Statistical Office of Thailand, and constructs a Code of Practice and indicators for quality management of official statistics in Thailand. Official statistics for quality management from three international agencies include the United Nations Statistics Division (UNSD), European Statistical System (Eurostat), and International Monetary Fund (IMF). Factor analysis is used to determine the important indicators and their respective weights. The research shows that a Code of Practice for quality management of official statistics in Thailand should be comprised of 9 rules and 35 common indicators.

The 3 papers on energy economics are as follows. The first paper is by Aumnad Phdungsilp (College of Innovative Technology and Engineering, Dhurakij Pundit University, Thailand), on "Projections of Energy Use and Carbon Emissions for Bangkok, Thailand". Cities around the world have developed innovative plans and strategies to reduce rampant and uncontrolled energy use and $\mathrm{CO}_{2}$ emissions. It is not surprising that many cities have adopted long-term emission reduction goals. However, a detailed analysis of energy use and the resulting carbon emissions are rare in developing countries. This paper presents historical trends of energy demand and energy-related $\mathrm{CO}_{2}$ emissions for Bangkok, Thailand. The $\mathrm{CO}_{2}$ emissions account for the use of fossil fuels only. It also presents the projections of energy use and $\mathrm{CO}_{2}$ emissions from 2010 to 2050. Using a bottom-up energy model and scenario analysis, the paper employs a Long-range Energy Alternative Planning (LEAP) system to simulate four sectors in Bangkok. The results identified by the BAU (business-as-usual) scenario indicate that total energy is expected to reach 54,560 kilotonne of oil equivalent (ktoe) with 191 million tonne $\mathrm{CO}_{2}\left(\mathrm{Mt}-\mathrm{CO}_{2}\right)$ by 2050 . Under the alternative scenario, if all policy interventions are implemented simultaneously, the potential for energy-savings and reduced $\mathrm{CO}_{2}$ emissions in 2050 are estimated to be 32,120 ktoe and 106.19 Mt- $\mathrm{CO}_{2}$. Other international cities may wish to apply the strategies and analytical approaches presented in this paper for developing appropriate policies and measures in their own jurisdictions.

Anurak Choeichum (College of Innovative Technology and Engineering, Dhurakij Pundit University, Thailand), Narongdech Keeratipranon (College of Innovative Technology and Engineering, Dhurakij Pundit University, Thailand), and Chaiyaporn Khemapatapan (College of Innovative Technology and Engineering, Dhurakij Pundit University, Thailand) consider "Multi-fuel Allocation for Power Generation 
Using Genetic Algorithms". The ever increasing growth of energy consumption has stimulated an energy crisis, not only in terms of energy demand, but also the impact of climate change from greenhouse gas (GHG) emissions. Renewable energy sources (RES) have high potential toward sustainable development, with a wide variety of socioeconomic benefits, including diversification of energy supply and creation of domestic industry. This paper presents a solution to optimal multi-fuel allocation for the electric power generation planning problem via genetic algorithms (GA). The objective is to maximize the electric power energy output and minimize generation cost. This is a difficult problem because of its data variation and volatility. GA can provide an appropriate heuristic search method and return an actual or near optimal solution. This paper uses some heuristics during crossover and mutation for tuning the system to obtain a better candidate solution. An experimental result showed significantly improved results compared with other techniques. The results in this paper should be useful for connecting power generation with economic growth.

The next paper is by Phatcharasak Phawanaphinyo (College of Innovative Technology and Engineering, Dhurakij Pundit University, Thailand), Narongdech Keeratipranon (College of Innovative Technology and Engineering, Dhurakij Pundit University, Thailand), and Chaiyaporn Khemapatapan (College of Innovative Technology and Engineering, Dhurakij Pundit University, Thailand) on "Optimal Active Energy Loss with Feeder Routing and Renewable Energy for Smart Grid Distribution". Electric power is the main energy source for a modern society. Good management of electric power cycle is essential for a sustainable society. The electric power cycle is composed of Generation, Transmission, Distribution, and Consumption. Smart Grid (SG) is a system that integrated traditional grids with Information and Communication Technology (ICT). In addition, SG has the ability to integrate electrical power supply from both to main power substation and Distributed Generation (DG), which compensates for the power demand during peak times. However, SG still has a similar problem to the original grid in terms of active power loss, from electric current injecting through the transmission line. This paper solves the active power loss problem by feeder routing using the Adjusting Dijkstra's Cost Method, follow by deciding the allocation position and sizing of DG by the use of Evolutionary Computing, namely Harmony Search (HS), Artificial Bee Colony
$(A B C)$, and Particle Swarm Optimization (PSO). The experiments evaluate the performance of the algorithm using power flow analysis, Backward / Forward Sweep Method, on the IEEE 33 bus system. From the experimental results, PSO provides the best performance. The overall active power loss in the cases of 3 DGs was reduced from 202.67 to $52.29 \mathrm{~kW}$, representing a reduction of $74.20 \%$.

The 2 papers on health \& medical economics are as follows. The first paper by Renu Sukharomana (Institute of Social and Economic Sciences, Dhurakij Pundit University, Thailand), and Chia-Lin Chang (National Chung Hsing University, Taiwan) examines the "Demand for Narcotics in Thailand, with Policy Implications". The paper examines the demand for narcotic drugs, based on Becker (1968), as purported rational behavior of human beings. The results from sampling surveys in eight provinces in Thailand in 2014, representing nationwide drug users/addicts, show that the demand for narcotics (amphetamines, ice drug, and marijuana) are price inelastic (between 0.533 and -0.701 ), as well as normal goods. The key econometric coefficients in models $A$ and $B$ are 0.192 and 0.0467 , respectively, and an increase in income will lead to an increase in the demand for narcotics. In addition, factors affecting the demand for narcotics are the age and age squared of the user, friendship, family member relationship, social relationship, reasons for drug use, risk behavior, and expected punishment. Public policy implications are also proposed and analysed.

This is followed by the second and final paper on health \& medical economics by Waraporn Jirapanthong (College of Creative Design and Entertainment Technology, Dhurakij Pundit University, Thailand) on "Computer Technology to Improve Medical Information in Bangkok, Thailand". Building hospital applications based on services allow hospitals and other organizations to cooperate and make use of business functions. Hospital information systems that involve extensive information exchange across hospitals and organization boundaries, such as patient profiles, can easily be automated. Service-based applications can be constructed by linking services from various providers using either a standard programming language or a specialized workflow language. This paper reviews the use of computer technology which supports health services in Bangkok, Thailand by developing a survey of health services in hospitals, in which the focus is on the attitudes and competence of medical students and physicians, and the availability of 
health services equipment; and analyzing and providing guidance via a web service that supports health services. A prototype of a web application is created to simulate situations of the use of computerbased devices for supporting clinical operations, involving 12 medical doctors and 3 patients. Two cases are analysed to demonstrate different situations of the web service. In such situations, stakeholders are requested to query patient information and specify the documents. The experiments have been evaluated by considering straightforward criteria to perform activities with the prototype to determine how accurate the documents are requested and specified, and evaluate how the health service performs efficiently.

The 3 papers on tourism economics are as follows. The first paper by Korakit Choomgrant (Kasetsart University, Thailand), and Renu Sukharomana (Institute of Social and Economic Sciences, Dhurakij Pundit University, Thailand) is concerned with "Heritage Tourism and Vibrant Life of the Baan Lao Community, Chao Phraya River, Bangkok, Thailand". The reputations of primary and secondary tourist destinations are hierarchically created through its value to the nation. Prioritizing a conservation project and tourism development can have major differences. Values attached to a destination by inhabitants are different from those of tourists, and are often influenced by the promotional campaigns designed by authorized agencies. A primary destination is then worthy of promotion and conservation as it serves a nation's purposes economically, socially and politically, while a destination that is not corresponding in such ways is usually disregarded. Koh Kret is an established primary tourism destination for domestic visitors, though not for international visitors. However, the Baan Lao Community can be developed as a secondary tourism destination for visitors to Koh Kret. Koh Kret and Baan Lao Community in Thailand are illustrations of significance and value. By understanding the Baan Lao community's significance, value and values, it is an opportunity to develop the area as a secondary tourist destination, and help preserve the way of life of local inhabitants along the Chao Phraya River in Bangkok, Thailand.

Aswin Sangpikul (College of Tourism and Hospitality, Dhurakij Pundit University, Thailand) considers "Ecotourism Impacts on the Economy, Society and Environment of Thailand". During the past decade, there have been a number of ecotourism studies in various disciplines to provide a knowledge foundation for sustainable tourism development.
However, most prior studies have examined the contributions of the ecotourism destinations in the economic and/or environmental dimensions. Little research has investigated the contributions of the ecotourism businesses in terms of business practices and their products to the three dimensions of sustainable development. This paper examines how ecotourism tour operators and their guided tours contribute to the development of economic, social and environmental dimensions at ecotourism sites and local communities. Data were collected from ecotourism tour operators through the interview and observation methods, and the contents were analyzed in accordance with ecotourism concepts and principles. The paper reveals that the practices of tour operators and their guided tours contributed economic, social, and environmental benefits to the ecotourism destinations and local communities. Interestingly, this paper finds that the length (duration) and types of guided tours had different contributions and impacts on the three dimensions of sustainability. In particular, guided tours with a local visit contribute greater economic and social benefits to the local areas than tours without a local visit. Recommendations are provided to promote responsible ecotourism business.

The final paper on tourism economics is by Janpha Thadphoothon (College of Arts, Dhurakij Pundit University, Thailand) on "Taxi Drivers' Cross-cultural Communication Problems and Challenges in Bangkok, Thailand". The paper reports an investigation of Thai taxi drivers' cross-cultural communication problems and challenges by synthesizing the research findings from two related studies: (1) a classroom investigation of Thai taxi drivers' communication challenges; and (2) a study of Thai taxi drivers' English language competence. The findings reveal that Thai taxi drivers had relatively low level of English competence, and had experienced three cross-cultural communication problems and challenges in the language, cultural, and attitudinal domains. Efforts to improve their English skills need to take into consideration the nature of their work and work conditions.

The 8 papers on global software are as follows. The first paper is by Winyu Niranatlamphong (College of Creative Design and Entertainment Technology, Dhurakij Pundit University, Thailand), and Worasit Choochaiwattana (College of Creative Design and Entertainment Technology, Dhurakij Pundit University, Thailand) on "A Hybrid Knowledge Discovery System Based on Items and Tags". Exponentially increasing knowledge in a management system is the main cause 
of the overload problem. Development of a recommender service embedded in the management system is challenging. This paper proposes a hybrid approach by combining an item-based recommendation technique (collaborative filtering technique) with a tag-based recommendation technique (content based filtering technique). In order to evaluate the performance of the proposed hybrid approach, a group of knowledge management system users are invited as participants in the research. Participants are asked to use the prototype of a management system embedded within the knowledge recommender service for four months, which guarantees that each interaction by participants with knowledge items are recorded. A confusion matrix is used to compute accuracy of the proposed hybrid approach. The results of the experiments reveal that the hybrid approach outperforms both item-based and tag-based approaches. The hybrid approach seems to be a promising technique for a recommender service in the knowledge management system.

This is followed by Banyapon Poolsawas (Department of Interactive Design and Game Development, College of Creative Design and Entertainment Technology, Dhurakij Pundit University, Thailand), and Winyu Niranatlamphong (Department of Digital Creative Designs, College of Creative Design and Entertainment Technology, Dhurakij Pundit University, Thailand) on "Using a Game Development Platform to Improve Advanced Programming Skills". A computer game is one of the most efficient instructional media for improving learners' programming skills. Implementing a game development platform or a game engine as an instruction tool provides benefits to learners. This paper observes progress in the learning process, and measures how long learners take to find solutions. The participants in the experiment were divided into two groups. The first group used traditional instructional media, such as lecturing, studying class materials, and solving assigned programming assignments. On the other hand, the second group attended the lectures, similar to the first group, and used a game development platform as instructional media to solve assigned programming assignments. The results showed that the progressive skills of the Game Development Platform learners were higher, and the problem-solving time they spent was lower.

Natapat Areerakulkan (College of Innovative Technology and Engineering, Dhurakij Pundit University, Thailand) considers "Quadratic Approximation of the Newsvendor Problem with
Imperfect Quality”. The paper presents a newsvendor problem in a fuzzy environment by introducing product quality as a fuzzy variable, and product demand as a probability distribution in an economic and supply chain management environment. In order to determine the optimal order quantity, a methodology is developed where the solution is achieved using a fuzzy ranking method combined with a quadratic programming problem approximation. Numerical examples are provided and compared in both situations, namely fuzzy and crisp. The results of these numerical examples show that the decision maker has to order a higher quantity when product quality is a fuzzy variable. The model can be useful for real world problems when historical data are not available.

The next paper is by Piyanuch Chaipornkaew (College of Innovative Technology and Engineering, Dhurakij Pundit University, Thailand), Takorn Prexawanprasut (College of Innovative Technology and Engineering, Dhurakij Pundit University, Thailand), and Michael McAleer (National Tsing Hua University, Taiwan) on "You've Got Email: A Workflow Management Extraction System". Email is one of the most powerful tools for communication. Many businesses use email as the main channel for communication, so it is possible that substantial data are included in email content. In order to help businesses grow faster, a workflow management system may be required. The data gathered from email content might be a robust source for a workflow management system. This research proposes an email extraction system to extract data from any incoming emails into suitable database fields. The database, which is created by the program, has been planned for the implementation of a workflow management system. The research is presented in three phases: (1) define suitable criteria to extract data; (2) implement a program to extract data, and store them in a database; and (3) implement a program for validating data in a database. Four criteria are applied for an email extraction system. The first criterion is to select contact information at the end of the email content; the second criterion is to select specified keywords, such as tel, email, and mobile; the third criterion is to select unique names, which start with a capital letter, such as the names of people, places, and corporates; the fourth criterion is to select special texts, such as Co. Ltd, .com, and www. The empirical results suggest that when all four criteria are considered, the accuracy of a program and percentage of blank fields are at an acceptable level compared with the results from other 
criteria. When four criteria are applied to extract 7,340 emails in English, the accuracy of this experiment is approximately $68.66 \%$, while the percentage of blank fields in a database is approximately 68.05. The database created by the experiment can be applied in a workflow management system.

Worasit Choochaiwattana (College of Creative Design and Entertainment Technology, Dhurakij Pundit University, Thailand) proposes "An Academic Search Engine for Personalized Rankings". Rapidly increasing information on the Internet and the World Wide Web can lead to information overload. Search engines become important tools to help WWW users to discover information. Exponential increases in published research papers, academic search engines become indispensable tools to search for papers in their expertise and related fields. In order to improve the quality of search, an academic search engines' capability should be enhanced. This paper proposes a search engine for personalized rankings. In order to evaluate the performance of personalized rankings, thirty-five graduate students from the Department of Web Engineering and Mobile Application Development at Dhurakij Pundit University are participants in the research experiment. Participants are asked to use a prototype of an academic search engine to find and bookmark any research papers according to their interests, which would guarantee that each participants' list of interesting research papers could be recorded. Normalized Discounted Cumulative Gain (NDCG) is used as a metric to determine the performance of the personalized rankings. The experiments suggest that the personalized rankings outperform the original search rankings. Hence, the proposed academic search engine with personalized ranking benefits research paper discovery.

"Creative and Learning Processes Using Gamebased Activities" are evaluated by Wilawan Inchamnan (College of Creative Design and Entertainment Technology, Dhurakij Pundit University, Thailand), and Karuna Yamplay (College of Creative Design and Entertainment Technology, Dhurakij Pundit University, Thailand). The paper gains a better understanding of how gameplay activities facilitate the creative learning process, reviews learning objects as game elements that influence creativity and learning outcomes, and focuses on learning activity in terms of a series of actions, namely goals, action and interaction, and interpretation. The series should be an element of object learning through game elements, that are adapted from a collection of content items, practice items, and assessment within game tasks. The findings illustrate the relationship between the series of actions within classroom activities, show the significant impact of learning outcomes and the series of actions' learning, and facilitate creative learning processes. The paper proposes a method for understanding the relationships between the learning processes that players undertake during gameplay, and the components of the game that allow these processes to occur. This method was synthesized from the focus group by considering the relationships of their learning outcomes and creative processes within game activities. Previous research studied the creative potential in puzzle game play in the process. The pilot participants in the study adapted the process that was observed during the game "Online Gunz 2: The Second Duel", and were recorded their learning outcomes. The anticipated outcomes represented how video games foster learning processes and creative processes. The results illustrate a significant conceptual method as interrelationships between meaningful learning and creative potential within a game-based activities.

This is followed by Waraporn Jirapanthong (College of Creative Design and Entertainment Technology, Dhurakij Pundit University, Thailand) on "Personal Software Process with Automatic Requirements Traceability to Support Startups". The paper applies Personal Software Process (PSP) for software development activities, and uses PSP scripts to follow the activities in software development. In particular, we have adapted a development script in order to enable automatic traceability. The script is the cyclical process that is designed for developing a large program in a sequence of small incremental steps. Moreover, we have extended an XTraQue tool to enable an automatic traceability during using PSP. This enables the completeness of traceability during using PSP. The Part-of-Speech (POS) embedded XML-based templates of software artefacts for PSP-based development, that is, functional requirements (FR), use case, and class diagram are defined. We perform an explanatory case study in order to evaluate the effectiveness between manual and automatic traceability during the personal software process (PSP). In particular, the causal links between software artefacts created during software development are socalled traceability relations. The result evaluation are concerned with precision and recall measures on the creation of traceability relations.

The final paper on global software is by Aurawan Imsombut (College of Creative Design and 
Entertainment Technology, Dhurakij Pundit University, Thailand), and Jesada Kajornrit (College of Innovative Technology and Engineering, Dhurakij Pundit University, Thailand) on "Comparing Statistical and Data Mining Techniques for Enrichment Ontology with Instances". Enriching instances into an ontology is an important task because the process extends knowledge in ontology to cover more extensively the domain of interest, so that greater benefits can be obtained. There are many techniques to classify instances of concepts with two popular techniques being the statistical and data mining methods. The paper compares the use of the two methods to classify instances to enrich ontology having greater domain knowledge, and selects a conditional random field for the statistical method and feature-weight k-nearest neighbor classification for the data mining method. The experiments are conducted on tourism ontology. The results show that conditional random fields methods provide greater precision and recall value than the other, specifically, F1-measure is $74.09 \%$ for conditional random fields and $60.04 \%$ for featureweight k-nearest neighbor classification.

\section{ACKNOWLEDGEMENT}

For financial support, the first author wishes to thank the National Science Council, Ministry of Science and Technology (MOST), Taiwan, and the second author is most grateful to the Australian Research Council and the National Science Council, Ministry of Science and Technology (MOST), Taiwan.

Received on 16-02-2017

Accepted on 13-05-2017

Published on 09-06-2017

DOI: https://doi.org/10.6000/1929-7092.2017.06.20

(C) 2017 Chang and McAleer; Licensee Lifescience Global.

This is an open access article licensed under the terms of the Creative Commons Attribution Non-Commercial License (http://creativecommons.org/licenses/by-nc/3.0/) which permits unrestricted, non-commercial use, distribution and reproduction in any medium, provided the work is properly cited. 